\title{
A RARE COMPLICATION OF ACUTE APPENDICITIS - CASE PRESENTATION
}

\author{
Dan DUMITRESCU ${ }^{1,3} \bowtie$, Costel SAVLOVSCHII,3, Sorin OPRESCU ${ }^{1,3}$, Dragos SERBAN ${ }^{1,3}$, \\ Sebastian GRADINARU ${ }^{1,3}$, Tiberiu TROTEA ${ }^{1,3}$, Bogdan SOCEA ${ }^{2,3}$, Catalin ALIUS ${ }^{1}$, \\ Victor DUMITRESCU ${ }^{1,3}$
}

${ }^{1}$ Emergency University Hospital Bucharest, General Surgery Clinic IV, Bucharest, Romania

${ }^{2}$ Emergency Clinical Hospital „St Pantelimon“ General Surgery Clinic, Bucharest Romania

3 „Carol Davila“ University of Medicine and Pharmacy, Bucharest, Romania

Received 17 Jan 2019, Accepted 20 Febr 2019

https://doi.org/10.31688/ABMU.2019.54.1.28

\begin{abstract}
Introduction. Considered by many authors a vestigial structure, the appendix is a small dimensions organ with mostly unknown functions. Acute appendicitis is the most common condition of the ileocecal appendix, having multifaceted clinical manifestations, often masquerading as various unrelated syndromes, but causing increased morbidity, especially when diagnosed late. Although the disease could manifest at any age, there is a progressive increase of its incidence from birth, with a maximum between 10 to 40 years.
\end{abstract}

Case presentation. We report the case of an 84 years-old female patient, who presented with significant abdominal pain in the lower quadrants, mainly in the right iliac fossa and in whom the CT examination was suggestive of a utero-appendicular fistula, a very rare complication in daily practice and even more seldom encountered in the elderly.

Conclusions. Acute appendicitis remains a condition for which surgery is still the optimum treatment, especially in the case of an elderly patient having a radiologically suspected fistula with the uterus that could

\section{Résumé}

Une complication rare d'appendicite aigue - présentation de cas

Introduction. De petite dimension, avec un rôle presque inconnu, l'appendice est considéré un organe vestigial par beaucoup des auteurs. L'appendicite aiguë est la plus fréquente maladie de l'appendice iléocæcal ; elle constitue une urgence chirurgicale avec de multiples manifestations qui se superposent souvent sur d'autres syndromes avec une importante morbidité surtout si le diagnostic est retardé. Malgré le fait que la maladie peut survenir à tous les âges, une croissance progressive est constatée sur l'incidence à la naissance avec un pic entre 10 et 40 ans.

Rapport de cas. On va présenter le cas d'une patiente adressée au service de chirurgie ; Madame X, 84 ans, présente des douleurs dans l'étage abdominal inférieur et plus intenses dans la fosse iliaque droite. Lexamen CT montre des images en faveur d'une fistule appendiculaire-utérine, une complication très rare au quotidien surtout pour les patients âgés. 
easily lead to septic gynecological complications and possibly progression to multiple organ failure.

Keywords: appendicitis, fistula, diagnosis, appendicitis in the elderly.

\section{INTRODUCTION}

Acute appendicitis is one of the most frequent clinical situations which prompts urgent surgery and is more common in young patients, but also described in the elderly. Its diagnosis might be difficult in view of poor compliance in children and associated comorbidities in the ageing population. History and clinical examination are crucial in establishing the correct diagnosis in younger patients, whereas in the adult and the elderly population one requires additional investigations such as computed tomography in order to rule out the numerous differentials that can mimic acute appendicitis.

\section{Case presentation}

We report the case of an 84 years-old female patient, from an urban area, who presented with moderate abdominal pain in the lower abdomen, especially in the right iliac fossa, which started approximatively 2 weeks ago, has increased progressively and was not associated with nausea, vomiting or alteration of her bowel habits. Clinical examination revealed a moderately painful abdomen in the hypogastrium and the right iliac fossa, with guarding, but no rebound

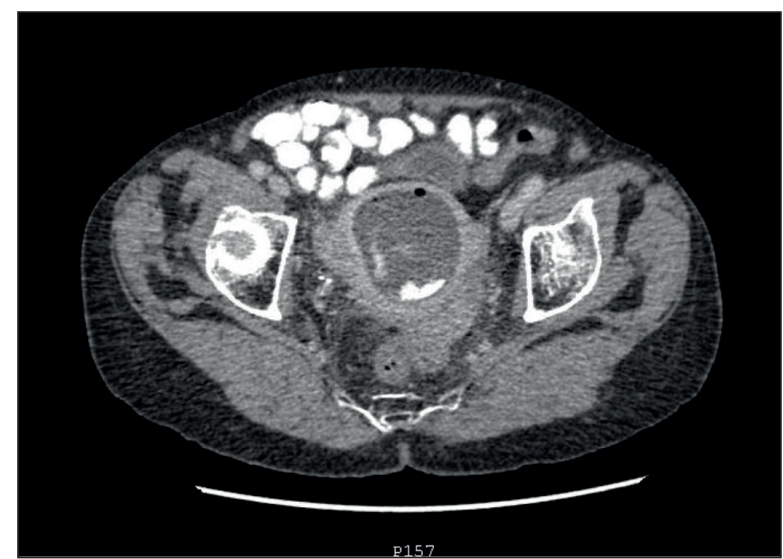

Figure 1. CT scan showing a significant enlargement of the uterine cavity filled with fluid, air and oral contrast.
Conclusions. L'appendicite aiguë reste l'une des maladies pour lesquelles la chirurgie est la meilleure solution de traitement, en particulier dans cette situation, dans le cas d'une patiente âgée, avec la suspicion d'une fistule impliquant l'utérus, un organe dont la pathologie infectieuse non traitée peut conduire relativement facilement à des complications graves SIRS / MSOF.

Mots-clés: appendicite, fistule, diagnostic, appendicite chez les personnes âgées.

tenderness or muscle contracture and no other relevant findings.

The blood tests results showed elevated WBC with neutrophilia and mild anemia, with no changes in the biochemistry and coagulation panels.

A computed tomography (CT) of the abdomen and the pelvis, with IV and oral contrast, demonstrated a significant enlargement of the uterine cavity filled with fluid, air and oral contrast (Fig. 1,2). The right lateral wall of the uterine cavity communicated through a broad, ill defined, fistulous tract, with the lower pole of the appendix (Fig. 3), suggesting that the fistula might be originating from an acutely inflamed appendix (Fig. 4).

We decided to proceed with urgent surgery through a pubio-umbilical median laparotomy. Intraoperatively, the uterus was enlarged, hyperemic, elastic, with a retro-uterine inflammatory mass incorporating the posterior wall of the uterus, the right adnexa, the cecum, portions of the small bowel and the sigmoid. After careful adhesion-lysis and release of the sigmoid colon and the small bowel, a fistulous tract was identified between the appendix and the uterine cavity, prompting total hysterectomy with bilateral adnexectomy and appendicectomy. Postoperatively, the patient was admitted to the Intensive Care Unit for

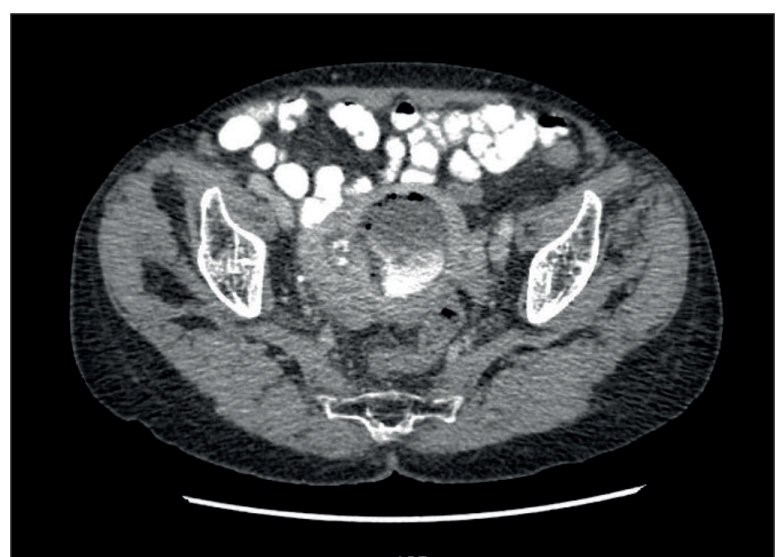

Figure 2. CT scan showing the uterine cavity filled with fluid, air and oral contrast. 


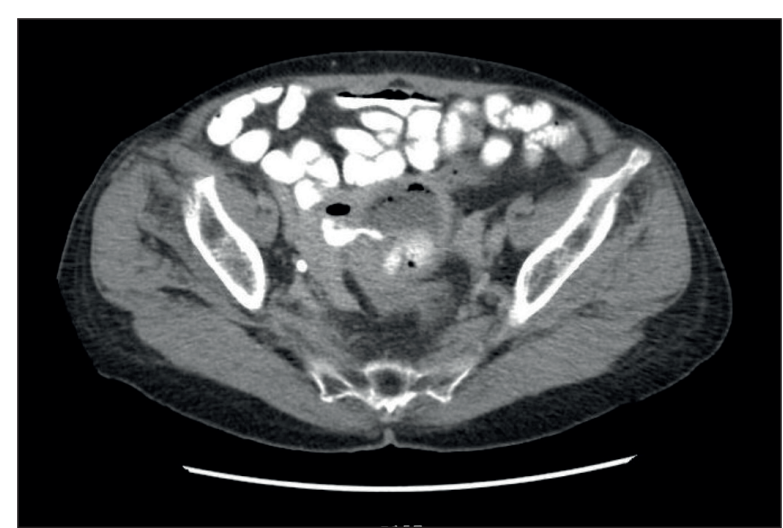

Figure 3. CT examination is suggestive of a utero-appendicular fistula.

24 hours and had a favorable evolution, with rapid remission of the postoperative ileus and tolerance of food intake. On day 5 post-op, the patient had an accidental fall causing a left neck of femur fracture, for which she required left lower limb immobilization with a Dessault bandage.

\section{Discussion}

Acute appendicitis continues to be the most common cause of surgical abdominal emergencies. It was often considered to be the disease of the young, but as a result of recent increases in lifetime expectancy, the incidence of acute appendicitis also increased in the elderly ${ }^{1,2}$.

The positive diagnosis of acute appendicitis in younger patients is most often based on history and clinical examination, the imaging and laboratory results providing reassurance for the surgical team. In the elderly, such as in our case, because of associated comorbidities, the clinical picture might be silent and the incidence is much rarer, all these making a positive diagnosis more difficult, thus the need for supplementary investigations $s^{3,4}$.

Delay in presentation was found by many authors to be the reason behind the higher rate of perforation seen in the elderly population ${ }^{1,2,5,6}$.

CT scan was essential in establishing the diagnosis of acute appendicitis with utero-appendiceal fistula, reiterating the important role of imaging in the elderly patients, where one could encounter numerous differential diagnoses such as: acute diverticulitis with fistulous complications? ${ }^{7}$, complicated Crohn's disease, cecum tumors, entero-uterine fistula, inflammatory or tumoral gynecological conditions, and various other causes of acute abdomen ${ }^{4,8-11}$.

The surgical intervention could be performed either open or laparoscopically, but in this situation the

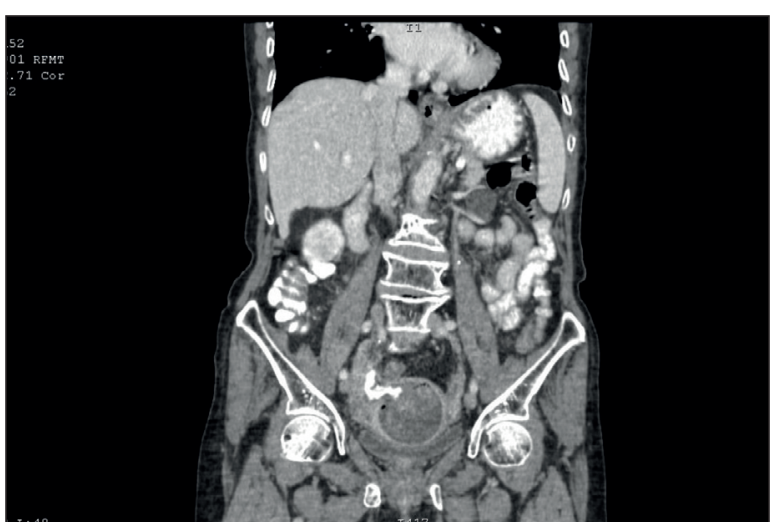

Figure 4. CT scan. A broad fistulous tract on the right lateral wall of the uterine cavity, possibly between the appendix and the uterus.

surgeon decided for a median laparotomy, in order to examine cautiously the whole peritoneal cavity and to eliminate a synchronous lesion and the mirage of the first lesion in a frail elderly patient ${ }^{12-14}$.

\section{Conclusions}

Acute appendicitis remains a condition for which surgery is still the optimum treatment, especially in the case of an elderly patient having a radiologically suspected fistula with the uterus that could lead easily to septic gynecological complications and possibly progression to MSOF.

Adequate postoperative care and nursing are of paramount importance even after the initial surgery especially in the elderly patients in whom complications occur easily and hinder favorable outcomes.

\section{Compliance with Ethics Requirements:}

"The authors declare no conflict of interest regarding this article"

"The authors declare that all the procedures and experiments of this study respect the ethical standards in the Helsinki Declaration of 1975, as revised in 2008(5), as well as the national law. Informed consent was obtained from the patient included in the study".

\section{References}

1. Popescu I. Patologia apendicelui vermiform. Tratat de Chirurgie, vol IX, Editura Academiei Romane, Bucuresti, 2009:287-288.

2. Omari AH, Khammash MR, Qasaimeh GR, et al. Acute appendicitis in the elderly: risk factors for perforation. World $J$ Emerg Surg. 2014; 9:6

3. Segev L, Keida A, Schrier I et al. Acute appendicitis in the elderly in the twenty-first century. Journal of Gastrointestinal Surgery. 2015;19(4):730-735. 
4. Pooler BD, Lawrence EM, Pickhardt PJ. MDCT for suspected appendicitis in the elderly: diagnostic performance and patient outcome. Emergency Radiology. 2012;19(1):27-33.

5. World Health Organization. Active ageing: a policy framework. Available at: whqlibdoc.who.int/hq/2002/who_ nmh_nph_02.8.pdf. Accessed 10 Jan 2019.

6. Savlovschi C, Serban D, Trotea T, Borcan R, Dumitrescu D. Post-surgery morbidity and mortality in colorectal cancer in elderly subjects. Chirurgia (Bucharest). 2013;108(2):177-9.

7. Bobic S, Socea B, Diaconu C, et al. The therapeutic management in colonic diverticular disease - a review. Research and Science Today 2018; Suppl 2:66-80

8. Hoffer FA, Ablow RC, Gryboski JD. Primary appendicitis with an appendico-tuboovarian fistula. AJR Am J Roentgenol. 1982;138(4):742-3.

9. Dumitrescu D, Savlovschi C, Borcan R, et al. Caz clin ic - hernie diafragmatica voluminoasa - abdomen acut chirurgical: dificultati diagnostice si terapeutice. Chirurgia (Bucharest). 2011;106(5):657-600.

10. Socea B, Carâp A, Rac-Albu M, Constantin V. The value of serum bilirubin level and of white blood cell count as severity markers for acute appendicitis. Chirurgia (Bucharest). 2013; 108(6): 829-834

11. Socea B, Smaranda A, Nica A, et al. Postcolonoscopy acute appendicitis - our case series and review of the literature. Arch Balk Med Union 2018; 53(4):313-315.

12. Kirshtein B, Perry ZH, Mizrahi S, Lantsberg L. Value of laparoscopic appendectomy in the elderly patient. World Journal of Surgery. 2009;33(5):918-922.

13. Constantin V, Carap A, Nica Anca, Smaranda A, Socea B. Appendiceal diverticulitis - a case report. Chirurgia (Bucharest). 2017;112(1): 82-84.

14. Socea B, Nica Anca, Smaranda C, et al. Solitary cecum diverticulitis - a surprising diagnosis. Arch Balk Med Union. 2017;52(4): 467-470. 